\title{
ChemComm
}

\section{The drastic effect of cobalt and chromium catalysts in the borylation of arylzinc reagents $\uparrow$}

Cite this: Chem. Commun., 2016, 52, 7009

Received 13th April 2016,

Accepted 28th April 2016

DOI: $10.1039 / c 6 c c 03086 f$

www.rsc.org/chemcomm

A new synthetic approach to arylboronic esters from arylzinc reagents with boryl electrophiles $\mathrm{MeOB}(\mathrm{OR})_{2}$ has been developed. Furthermore, this protocol could be applied to the cyclization/borylation of alkynylaryl iodides to afford cyclized vinylboronic esters.

Arylboronic esters are recognized as being indispensable building blocks in organic synthesis because of their stability and wide range applicability to $\mathrm{C}-\mathrm{X}(\mathrm{X}=\mathrm{C}, \mathrm{N}$ and $\mathrm{O})$ bond-forming reactions in chemical, medicinal and materials science. ${ }^{1}$ Over the past 20 years, transition-metal-catalysed borylations of aryl (pseudo)halides with diborons, hydroboranes or metal-boryl reagents have been developed using $\mathrm{Pd}, \mathrm{Rh}, \mathrm{Ni}, \mathrm{Cu}, \mathrm{Zn}, \mathrm{Fe}$ and Co complexes. ${ }^{2}$ These methods facilitate the concise synthesis of arylboronic esters bearing useful functional groups (route a, Scheme 1). More recently, the synthetic strategies used to produce arylboronic esters have shifted to favour the direct $\mathrm{C}-\mathrm{H}$ borylation of arenes, which has been rapidly evolved by precious metal catalysts such as Rh and Ir (route b). ${ }^{3,4}$ Moreover, very recently, the direct borylations have been also accomplished by using abundant and inexpensive transition-metal catalysts. ${ }^{5}$ In contrast, transition-metal-free borylation protocols, such as electrophilic borylations of electron-rich arenes (route c), ${ }^{6}$ the Sandmeyer-type borylation (route d), ${ }^{7}$ and boryl substitution reactions with borylsilanes $^{8}$ or borylzincates ${ }^{9}$ (route e), have been frequently reported, although there are still problems with these strategies, such as their narrow substrate scope, loss of the boron component and/or the scarcity of suitable boron sources.

A classical but powerful method for the synthesis of arylboronic esters is the substitution of aryllithium or arylmagnesium reagents with trialkylboric esters. ${ }^{10}$ This method, however, suffers from poor functional group tolerance. Conversely, compared with the above organometallics, organozinc compounds are

Department of Applied Chemistry, Graduate School of Engineering, Hiroshima University, Higashi-Hiroshima 739-8527, Japan.

E-mail: kkome@hiroshima-u.ac.jp; Fax: +81-82-424-5494; Tel: +81-82-424-7747 $\dagger$ Electronic supplementary information (ESI) available: Additional experimental results, experimental procedures and characterisation of the products. See DOI: $10.1039 / \mathrm{c} 6 \mathrm{cc} 03086 \mathrm{f}$

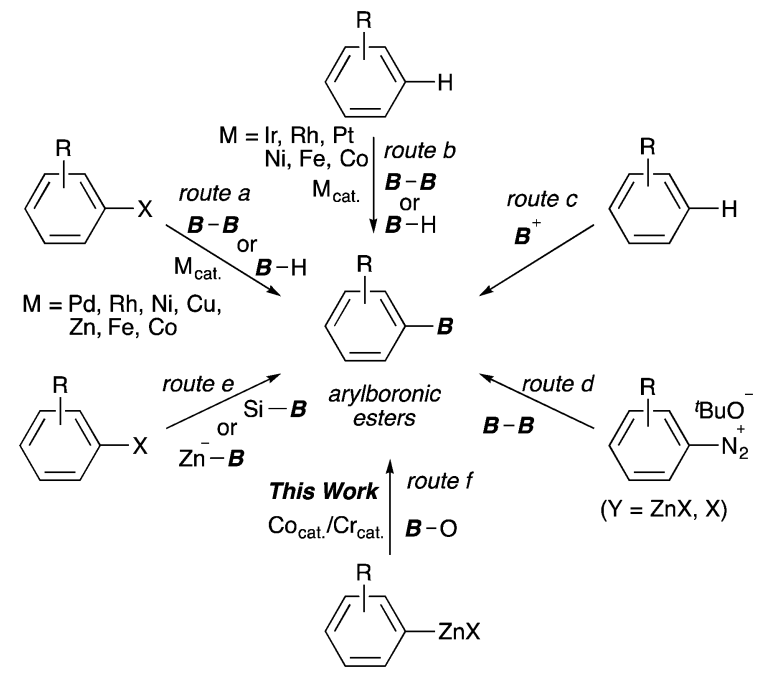

Scheme 1 Synthetic methods for arylboronic esters.

highly compatible with a broad range of polar functional groups due to the relatively weak ionic character of the $\mathrm{C}-\mathrm{Zn}$ bond, which may undergo chemoselective transformation. ${ }^{11}$ However, the nucleophilicity of organozinc reagents is quite low; therefore, their reactions with organic electrophiles often require the use of transitionmetal catalysts. ${ }^{12}$ Despite their high potential for the development of tractable organic transformations, the borylation of organozinc reagents using easy-to-handle boric esters has not been reported, ${ }^{13}$ except for highly electrophilic B-chlorocatecholborane and subporphyrins. ${ }^{14}$

Transmetalation is a highly effective route to drastically changing the reactivity of an organometallic species. For example, Takagi reported that highly nucleophilic arylchromium intermediates ${ }^{15}$ afforded by the reaction of arylzinc reagents with chromium(III) salts, underwent addition to aldehydes under mild conditions. A similar strategy of changing the nucleophilicity of organometallics via transmetalation has been demonstrated in the Nozaki-Hiyama-Kishi reaction. ${ }^{16}$ Here we report the marked additive effect of low-valence cobalt and chromium catalysts in 
Table 1 Effect of cobalt and chromium salts in the borylation of 4-tolZnl. LiCl with MeOBpin (2a) $)^{a}$

\begin{tabular}{|c|c|c|c|c|c|}
\hline \multirow[b]{2}{*}{ Entry } & \multicolumn{2}{|c|}{$\sum^{\mathrm{Znl} \cdot \mathrm{LiCl}}+\underset{\substack{\mathrm{MeOBpin} \\
(1.2 \text { equiv. })}}{2 \mathrm{a}}$} & $\begin{array}{c}\begin{array}{c}\text { additives } \\
\text { (mol \%) }\end{array} \\
\mathrm{Zn}, \mathrm{THF}, \\
60^{\circ} \mathrm{C}, 16 \mathrm{~h}\end{array}$ & $\underset{\mathrm{F},}{\mathrm{F}}$ & Bpin \\
\hline & \multicolumn{3}{|c|}{ Additives (mol\%) } & Zn ( $x$ equiv.) & Yield $^{b}(\%)$ \\
\hline 1 & \multicolumn{3}{|l|}{-} & - & Trace \\
\hline 2 & \multicolumn{3}{|l|}{$\mathrm{CrCl}_{3}(\text { thf })_{3}(20)$} & - & Trace \\
\hline 3 & \multicolumn{3}{|c|}{$\mathrm{CrCl}_{2}(20)$} & - & Trace \\
\hline 4 & \multicolumn{3}{|c|}{$\mathrm{CoBr}_{2} /$ xantphos (10), $\mathrm{CrCl}_{3}(\mathrm{thf})_{3}(20)$} & 2.0 & 73 \\
\hline 5 & \multicolumn{3}{|c|}{$\mathrm{CoBr}_{2} /$ xantphos (10), $\mathrm{CrCl}_{3}(\mathrm{thf})_{3}(20)$} & 0.5 & 67 \\
\hline 6 & \multicolumn{3}{|c|}{$\mathrm{CoBr}_{2} /$ xantphos (10), $\mathrm{CrCl}_{3}(\mathrm{thf})_{3}(20)$} & - & Trace \\
\hline 7 & \multicolumn{3}{|c|}{$\mathrm{CrCl}_{3}(\text { thf })_{3}(20)$} & 2.0 & Trace \\
\hline 8 & \multicolumn{3}{|c|}{$\mathrm{CoBr}_{2} /$ xantphos (10) } & 2.0 & 32 \\
\hline 9 & \multicolumn{3}{|c|}{$\mathrm{CoBr} /$ xantphos $(10),{ }^{c} \mathrm{CrCl}_{3}(\mathrm{thf})_{3}(20)$} & - & 13 \\
\hline 10 & \multicolumn{3}{|c|}{$\mathrm{CoBr} /$ xantphos $(10),{ }^{c} \mathrm{CrCl}_{2}(20)$} & - & 65 \\
\hline 11 & \multicolumn{3}{|c|}{$\operatorname{CoBr}(10)^{c}$} & - & Trace \\
\hline 12 & \multicolumn{3}{|c|}{$\mathrm{CoBr} / \mathrm{dppe}(10),{ }^{c} \mathrm{CrCl}_{2}(20)$} & - & 53 \\
\hline
\end{tabular}

${ }^{a}$ All reactions were carried out in the presence of TMSCl (1.2 equiv.). ${ }^{b}$ NMR yield. ${ }^{c}$ The borylation was performed after reduction with $20 \mathrm{~mol} \%$ zinc powder to form the low-valence cobalt complex.

the borylation of arylzinc reagents with $\mathrm{MeOB}(\mathrm{OR})_{2}$ as the boryl electrophile in the presence of TMSCl (route f). Furthermore, this protocol could be applied to the direct synthesis of arylboronic esters from ubiquitous aryl halides under $\mathrm{CoBr}_{2}$, xantphos and $\mathrm{CrCl}_{3}(\mathrm{thf})_{3}$ catalyst systems in the presence of $\mathrm{Zn}$.

We began by examining the borylation of the preformed 4- $\mathrm{MeC}_{6} \mathrm{H}_{4} \mathrm{ZnI} \cdot \mathrm{LiCl}^{17}$ with 2-methoxy-4,4,5,5-tetramethyl-1,3,2dioxaborolane (2a, MeOBpin) as model substrates in the presence of TMSCl (1.2 equiv.) at $60{ }^{\circ} \mathrm{C}$ for $16 \mathrm{~h}$. These results are summarized in Table 1 . As expected, the arylzinc compound was inactive and hardly participated in the borylation, wherein the arylzinc remained unchanged after the reaction (Table 1, entry 1). ${ }^{18}$ The addition of the $\mathrm{CrCl}_{3}(\text { thf })_{3}$ or $\mathrm{CrCl}_{2}$ catalyst (20 mol\%) did not afford the arylboronic ester (entries 2 and 3). Conversely, we observed an unexpected effect arising from the combination of cobalt and chromium catalysts under reduction conditions (entries 4 and 5). Thus, a mixture of $\mathrm{CoBr}_{2} /$ xantphos $^{19}$ and $\mathrm{CrCl}_{3}(\text { thf })_{3}$ complexes in the presence of zinc powder (0.5-2.0 equiv.) effectively promoted the borylation, giving rise to 4 -tolylboronic pinacol ester (3aa) in satisfactory yields (67-73\%). Intriguingly, all the components, i.e. the cobalt, chromium and zinc reductants, are crucial for efficient borylation (entries 6-8). Finally, we found that low-valence cobalt and chromium complexes play important roles in the borylation reaction (entries 9 and 10). The role of the xantphos ligand is unclear, ${ }^{20}$ and it is not absolutely necessary to the borylation. There is no reaction in the absence of the ligand (entry 11); however, the presence of dppe afforded $3 a a$ in $53 \%$ yield (entry 12 ).

The cobalt/xantphos complex has been reported to be an equally effective catalyst for the transformation of aryl halides into arylzinc reagents under similar reduction conditions. ${ }^{21}$ Based on these reports and our previous work on cobalt-catalysed reactions, ${ }^{22}$ the present $\mathrm{Co} / \mathrm{Cr}$-catalysed borylation with arylzinc reagents was refined into a more simplified protocol starting
Table 2 Screening of the reaction conditions for $\mathrm{Co} / \mathrm{Cr}$-catalysed borylation starting from 4-tolyl bromide halides $1 \mathrm{a}$ with $\mathbf{2} \mathrm{a}^{\mathrm{a}}$

\begin{tabular}{|c|c|c|c|c|}
\hline $\mathrm{Me}$ & 1a & $\begin{array}{c}+\quad \mathrm{MeO}-\text { Bpin } \\
\mathbf{2 a} \\
(1.2 \text { equiv. })\end{array}$ & $\begin{array}{l}10 \mathrm{~mol} \% \mathrm{CoBr}_{2} \\
10 \mathrm{~mol} \% \text { xantphos } \\
20 \mathrm{~mol}^{2} \mathrm{CrCl}_{3}(\mathrm{THF})_{3} \\
\mathrm{Zn}(2.0 \text { equiv. }) \\
\mathrm{LiCl}(1.0 \text { equiv. }) \\
\mathrm{TMSCl}(1.2 \text { equiv. }) \\
\mathrm{THF}, 60^{\circ} \mathrm{C}, 16 \mathrm{~h}\end{array}$ & $\sum_{3 a a}^{B p i n}$ \\
\hline Entry & \multicolumn{3}{|c|}{ Change from standard conditions } & Yield $/ \%$ of $3 \mathbf{a a}^{a}$ \\
\hline 1 & \multicolumn{3}{|l|}{-} & $79(75)$ \\
\hline $2^{b}$ & \multicolumn{3}{|c|}{ Without TMSCl } & 27 \\
\hline 3 & \multirow{2}{*}{\multicolumn{3}{|c|}{$\begin{array}{l}\mathrm{CrCl}_{3}(\mathrm{bpy}) \text { in place of } \mathrm{CrCl}_{3}(\mathrm{THF})_{3} \\
\mathrm{CrCl}_{3}(1,10 \text {-phen }) \text { in place of } \mathrm{CrCl}_{3}(\mathrm{THF})_{3}\end{array}$}} & 12 \\
\hline 4 & & & & 4 \\
\hline $5^{c}$ & \multicolumn{3}{|c|}{1,10 -Phen in place of xantphos } & 60 \\
\hline
\end{tabular}

${ }^{a}$ NMR yield. The parenthesis value indicates an isolated yield. ${ }^{b}$ Reaction time: $48 \mathrm{~h} .{ }^{c}$ MeCN solvent was used instead of THF.

from 4-tolyl iodide (Table 2, entry 1). Without TMSCl, the desired boronic ester 3aa was obtained in low yield (27\%), even with a longer reaction time (entry 2). This result indicates robust $\mathrm{Cr}-\mathrm{O}$ bond formation during the reaction, because the bond appears to be difficult to cleave in the catalytic cycle without the aid of $\mathrm{TMSCl}^{23}$ Chromium complexes ligated by nitrogen ligands, ${ }^{24}$ such as 2,2'-bipyridyl (bpy) and 1,10-phenanthroline (1,10-phen), inhibit the borylation in THF solvent (entries 6 and 7). However, the borylation proceeded in acetonitrile with the replacement of xantphos with 1.10-phen, albeit with a slightly lower yield (entry 5). ${ }^{25}$

Having established the optimum conditions (Table 2, entry 1), we explored the substrate scope through the $\mathrm{Co} / \mathrm{Cr}$-catalysed borylation of various aryl bromides (Table 3). Electron-neutral (1b and 1c) and -rich aryl bromides (1d, 1e and 1f) are efficiently converted to the corresponding arylboronic acid pinacol esters 3 in $66-71 \%$ yields (entries $1-5$ ). However, electron-deficient aryl halides with inductively and/or resonance withdrawing substituents were less reactive (entries 6, 8, 10, 12, 14 and 17). In particular, the strongly electron-deficient aryl bromides bearing $\mathrm{CN}(\mathbf{1 j})$ and $\mathrm{CF}_{3}(\mathbf{1 k}, \mathbf{1 m})$ substituents were markedly less reactive towards trapping with 2a (entries 12, 14 and 17). Fortunately, a significant improvement was achieved by the replacement of $2 \mathbf{a}$ with 2-methoxy-5,5-dimethyl-1,3,2-dioxaborinane (MeOBnep, 2b), which is a less sterically hindered electrophile compared to $2 a^{26}$ This boronate preferentially afforded the desired boronic esters $\mathbf{3 j \mathbf { j }}$, 3kb and $\mathbf{3} \mathbf{m b}$ in good yields (entries 13, 15 and 18). We also explored the effect of the leaving group, such as the 2-methoxyethoxy substituent, on the boron 2, but such substituents did not significantly affect the reactivity. ${ }^{27}$ In the Co/Cr-catalysed borylation, trimethylsilyl aryls (11, entry 16) as well as heteroaryl skeletons such as indole (10, entry 21) and thiophene (1p, entry 22) also took part in the borylation. In contrast, the use of aryl chlorides leads to lower product yields.

The borylation reaction presumably involves the generation of aryl cobalt and aryl chromium intermediates. In contrast, the migratory insertion of an alkyne into both aryl-metal complexes has been established. ${ }^{25 b, 28}$ Based on these findings and our previous results, ${ }^{22}$ we assumed that if these aryl-metal complexes are active in alkyne-insertion reactions to form a vinyl-metal species, 
Table 3 Substrate scope for the Co/Cr-catalysed borylation of aryl halides

\begin{tabular}{|c|c|c|c|}
\hline $\begin{array}{l}\mathrm{Ar}-\mathrm{X} \\
\quad 1 \\
\mathrm{X}=\mathrm{Br}, \mathrm{I}\end{array}$ & $\begin{array}{c}+\quad \text { MeO[B] } \\
\text { (1.2 equiv.) } \\
{[\mathrm{B}]=\text { Bpin: } \mathbf{2 a}} \\
=\text { Bnep: } \mathbf{2 b}\end{array}$ & $\begin{array}{l}10 \mathrm{~mol}_{\% \mathrm{CoBr}_{2}} \\
10 \mathrm{~mol} \% \text { xantphos } \\
20 \mathrm{~mol} \% \mathrm{CrCl}_{3} \text { (thf) } \\
\mathrm{Zn}(2.0 \text { equiv.) } \\
\mathrm{LiCl}(1.0 \text { equiv.) } \\
\mathrm{TMSCl} \text { (1.2 equiv.) } \\
\mathrm{THF}, 60^{\circ} \mathrm{C}\end{array}$ & $\mathrm{Ar}_{3}$ \\
\hline
\end{tabular}

\begin{tabular}{llll}
\hline Entry & Ar-Br 1 & Time $/ \mathrm{h}$ & Product $\&$ yield \\
&
\end{tabular}$\%$

1
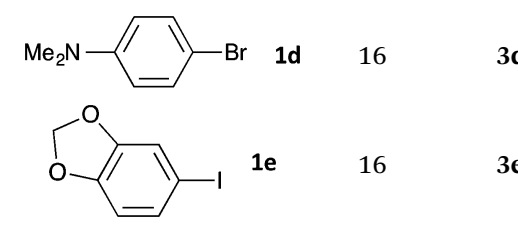

$16 \quad 3 e a$

67

$5^{b}$<smiles>COc1ccccc1I</smiles>

$\begin{array}{lll}48 & \text { 3fa } & 68 \\ & & \\ 16 & \text { 3gb } & 38 \\ 16 & \text { 3ga } & 66\end{array}$

6
$7^{c}$

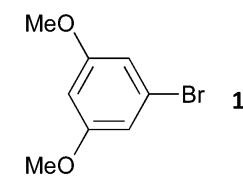

8

$9^{c}$

10

$12^{b}$

$13^{b, c}$

$14^{b}$

$15^{b, c}$

$16^{c}$

17

$18^{b, c}$

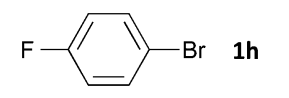

16

16

3ha

$3 h b$

62

$\mathrm{MeO}_{2} \mathrm{C}$

48
48

3ia

$3 i b$

74

$\mathrm{NC}$

3ja

$3 \mathbf{j b}$

$3 \mathbf{k a}$

$3 \mathbf{k b}$

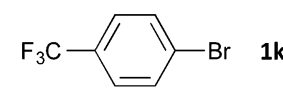

48<smiles>C[SiH2]c1ccc(Br)cc1</smiles>

24

\section{3lb}

$3 \mathrm{ma}$

$3 \mathrm{mb}$

3na

65

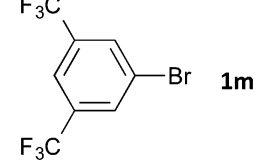

$\mathrm{MeO}_{2} \mathrm{C}$

$20^{b, c}$

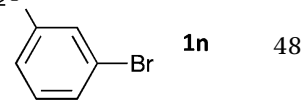

48

3nb $\quad 66$

21

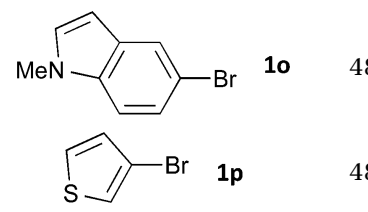

${ }^{a}$ Isolated yield. ${ }^{b} 2$ equivalents of the boryl electrophile were employed. ${ }^{c} \mathrm{MeOB}($ nep) was used instead of MeOB(pin).

and the products undergo a substitution reaction with boryl electrophiles under identical conditions to those presented above, a useful three-component reaction (carboboration) could be developed. The carboboration of alkynes is a very important process for the regio- and stereoselective synthesis of multisubstituted olefins. ${ }^{29}$ Similar catalytic reactions for alkynes ${ }^{13,30}$ have been reported; however, all examples employed carbon electrophiles. The transformation using boryl electrophiles has never been demonstrated, except in cases employing Grignard reagents. ${ }^{31}$ Our initial attempts at the addition/borylation of 4-octyne with 4-tolyl bromide 1a and MeOBpin 2a under identical conditions failed, wherein the major product is arylboronic ester 3aa. This may be because the reaction of the in situ generated aryls-metal species with the boryl electrophile is fast compared to the intermolecular reaction with the alkyne. Based on these experimental results, we next attempted the cyclisation/borylation of alkynyl aryl iodides 4 (Scheme 2). Having refined the conditions, ${ }^{32}$ the desired cyclisation/borylation was accomplished, affording the cyclised vinylboronic esters $\mathbf{5 a}, \mathbf{5 b}$ and $\mathbf{5 c}$ in 50,41 and $43 \%$ yields, respectively (Scheme 2). The stereochemistry of the products was determined by NOE measurements, which clearly indicated syn-carboboration. In addition, an alkynyl aryl iodide tethered with nitrogen also reacted to afford the corresponding boronic ester $\mathbf{5 d}$ in $26 \%$ yield.

Although the actual role of the cobalt catalyst is still unclear, the arylchromium(II) species seems to trigger the borylation step. Thus, the reaction of $4-\mathrm{MeC}_{6} \mathrm{H}_{4} \mathrm{CrCl}_{2}$ (prepared via the reaction of the $4-\mathrm{MeC}_{6} \mathrm{H}_{4} \mathrm{Li}$ with $\left.\mathrm{CrCl}_{3}(\mathrm{thf})_{3}\right)^{33}$ with MeOBpin afforded 3aa in only $3 \%$ GC yield. ${ }^{34}$ In contrast, the reaction of the $4-\mathrm{MeC}_{6} \mathrm{H}_{4} \mathrm{CrCl}$ provided $3 \mathrm{aa}$ in $67 \%$ yield.

In conclusion, we have reported a drastic additive effect for increasing the reactivity of arylzinc reagents, enabling the borylation of unreactive arylzinc compounds to afford various arylboronic esters. In addition, we found that this protocol could be applied to a more practical route to borylation starting from ubiquitous aryl halides. The easy-to-operate procedure avoids the preparation of air- and moisture-sensitive arylzinc reagents, making it more practical for arylboronic ester synthesis. Furthermore, cyclisation/borylation of arylalkynyl iodides was accomplished by the modified catalytic system to give cyclized vinylboronic esters, in which carboboration proceeded in an exclusively syn-addition manner. Control experiments revealed the important roles of low-valence cobalt and chromium in the borylation. This suggests that a key intermediate is an aryl

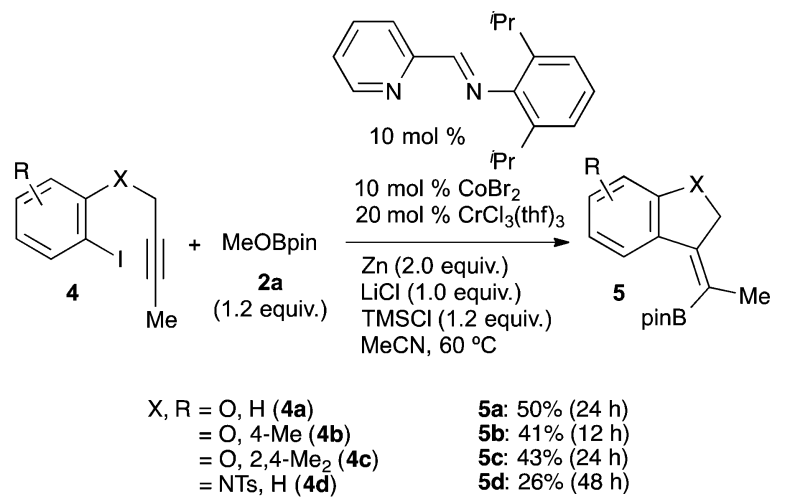

Scheme 2 Substrate scope for the Co/Cr-catalysed cyclisation/borylation. 
chromium(II) species, although more data are required in order to understand the mechanistic details of the reaction. Further studies on the mechanism and synthetic applications of the $\mathrm{Co} / \mathrm{Cr}$ catalyst system are currently underway in our laboratory.

This work was partially supported by a Grant-Aid for Scientific Research (KAKENHI) from the Ministry of Education, Culture, Sports, Science and Technology of Japan (No. 15K05502).

\section{Notes and references}

1 (a) N. Miyaura and A. Suzuki, Chem. Rev., 1995, 95, 2457; (b) D. G. Hall, Boronic Acids: Preparation and Applications in Organic Synthesis and Medicine, Wiley-VCH, Weinheim, 2005.

2 Recent reviews for the transition metal-catalyzed borylation of aryl (pseudo)halides: (a) W. K. Chow, O. Y. Yuen, P. Y. Choy, C. M. So, C. P. Lau, W. T. Wong and F. Y. Kwong, RSC Adv., 2013, 3, 12518; (b) M. Murata, Heterocycles, 2012, 85, 1795. With Pd: (c) J. Campos and S. Aldridge, Angew. Chem., Int. Ed., 2015, 54, 14159. With Rh: (d) M. Tobisu, H. Kinuta, Y. Kita, E. Rémond and N. Chatani, J. Am. Chem. Soc., 2011, 134, 115; (e) H. Kinuta, M. Tobisu and N. Chatani, J. Am. Chem. Soc., 2015, 137, 1593. With Ni: $(f)$ M. Tobisu, K. Nakamura and N. Chatani, J. Am. Chem. Soc., 2014, 136, 5587; (g) X.-W. Liu, J. Echavarren, C. Zarate and R. Martin, J. Am. Chem. Soc., 2015, 137, 12470; (h) T. Niwa, H. Ochiai, Y. Watanabe and T. Hosoya, J. Am. Chem. Soc., 2015, 137, 14313; (i) J. Zhou, M. W. Kuntze-Fechner, R. Bertermann, U. S. D. Paul, J. H. J. Berthel, A. Friedrich, Z. Du, T. B. Marder and U. Radius, J. Am. Chem. Soc., 2016, 138, 5250. With Cu: C. Kleeberg, L. Dang, Z. Lin and T. B. Marder, Angew. Chem., Int. Ed., 2009, 48, 5350. With Zn: $(j)$ S. Bose and T. B. Marder, Org. Lett., 2014, 16, 4562; ( $k$ ) S. K. Bose, A. Deißenberger, A. Eichhorn, P. G. Steel, Z. Lin and T. B. Marder, Angew. Chem., Int. Ed., 2015, 54, 11843. With Fe: $(l)$ R. B. Bedford, P. B. Brenner, E. Carter, T. Gallagher, D. M. Murphy and D. R. Pye, Organometallics, 2014, 33, 5940; (m) F. Labre, Y. Gimbert, P. Bannwarth, S. Olivero, E. Duñach and P. Y. Chavant, Org. Lett., 2014, 16, 2366. With Co: (n) W. Yao, H. Fang, S. Peng, H. Wen, L. Zhang, A. Hu and Z. Huang, Organometallics, 2016, DOI: 10.1021/acs.organomet.6b00161.

3 Review for the $\mathrm{Rh}$ or Ir catalysed aromatic $\mathrm{C}-\mathrm{H}$ borylation: (a) T. Ishiyama and N. Miyaura, J. Organomet. Chem., 2003, 680, 3; (b) I. A. I. Mkhalid, J. H. Barnard, T. B. Marder, J. M. Murphy and J. F. Hartwig, Chem. Rev., 2010, 110, 890; (c) J. F. Hartwig, Chem. Soc. Rev., 2011, 40, 1992; (d) A. Ros, R. Fernández and J. M. Lassaletta, Chem. Soc. Rev., 2014, 43, 3229.

4 (a) S. M. Preshlock, D. L. Plattner, P. E. Maligres, S. W. Krska, R. E. Maleczka and M. R. Smith, Angew. Chem., Int. Ed., 2013, 52, 12915; (b) S. Kawamorita, T. Miyazaki, H. Ohmiya, T. Iwai and M. Sawamura, J. Am. Chem. Soc., 2011, 133, 19310; (c) Y. Saito, Y. Segawa and K. Itami, J. Am. Chem. Soc., 2015, 137, 5193; (d) Y. Kuninobu, H. Ida, M. Nishi and M. Kanai, Nat. Chem., 2015, 7, 712; (e) With Pt: T. Furukawa, M. Tobisu and N. Chatani, J. Am. Chem. Soc., 2015, 137, 12211.

5 With Ni: (a) T. Furukawa, M. Tobisu and N. Chatani, Chem. Commun., 2015, 51, 6508; (b) H. Zhang, S. Hagihara and K. Itami, Chem. Lett., 2015, 44, 779. With Fe: (c) T. Hatanaka, Y. Ohki and K. Tatsumi, Chem. - Asian J., 2010, 5, 1657; (d) G. Yan, Y. Jiang, C. Kuang, S. Wang, H. Liu, Y. Zhangb and J. Wang, Chem. Commun., 2010, 46, 3170; (e) T. Dombray, C. G. Werncke, S. Jiang, M. Grellier, L. Vendier, S. Bontemps, J.-B. Sortais, S. Sabo-Etienne and C. Darcel, J. Am. Chem. Soc., 2015, 137, 4062. With Fe/Cu: $(f)$ T. J. Mazzacano and N. P. Mankad, J. Am. Chem. Soc., 2013, 135, 17258. With Co: $(g)$ J. V. Obligacion, S. P. Semproni and P. J. Chirik, J. Am. Chem. Soc., 2014, 136, 4133.

6 A. Del Grosso, M. D Helm, S. A. Solomon, D. Caras-Quintero and M. J. Ingleson, Chem. Commun., 2011, 47, 12459.
7 F. Mo, Y. Jiang, D. Qiu, Y. Zhang and J. Wang, Angew. Chem., Int. Ed., 2010, 49, 1846.

8 E. Yamamoto, K. Izumi, Y. Horita and H. Ito, J. Am. Chem. Soc., 2012, 134, 19997.

9 Y. Nagashima, R. Takita, K. Yoshida, K. Hirano and M. Uchiyama, J. Am. Chem. Soc., 2013, 135, 18730.

10 (a) H. C. Brown and T. E. Cole, Organometallics, 1983, 2, 1316; (b) J. W. Clary, T. J. Rettenmaier, R. Snelling, W. Bryks, J. Banwell, W. T. Wipke and B. Singaram, J. Org. Chem., 2011, 76, 9602.

11 P. Knochel and R. D. Singer, Chem. Rev., 1993, 93, 2117.

12 P. Knochel, M. A. Schade, S. Bernhardt, G. Manolikakes, A. Metzger, F. M. Piller, C. J. Rohbogner and M. Mosrin, Beilstein J. Org. Chem., 2011, 7, 1261.

13 N. Nakagawa, T. Hatakeyama and M. Nakamura, Chem. - Eur. J., 2015, 21, 4257.

14 (a) S. Claudel, C. Gosmini, J. M. Paris and J. Périchon, Chem. Commun., 2007, 3667; (b) R. Kotani, K. Yoshida, E. Tsurumaki and A. Osuka, Chem. - Eur. J., 2016, 22, 3320.

15 (a) Y. Ogawa, M. Mori, A. Saiga and K. Takagi, Chem. Lett., 1996, 1069; (b) Y. Ogawa, A. Saiga, M. Mori, T. Shibata and K. Takagi, J. Org. Chem., 2000, 65, 1031.

16 (a) K. Takai, K. Nitta and O. Fujimura, J. Org. Chem., 1989, 54, 4732; (b) K. Takai, N. Matsukawa, A. Takahashi and T. Fujii, Angew. Chem., Int. Ed., 1998, 37, 152.

17 A. Krasovskiy, V. Malakhov, A. Gavryushin and P. Knochel, Angew. Chem., Int. Ed., 2006, 45, 6040.

18 After the reaction, treatment of the reaction mixture with $\mathrm{I}_{2}$ afforded 4-iodotoluene in nearly quantitative yield.

19 M. M. P. Grutters, C. Müller and D. Vogt, J. Am. Chem. Soc., 2006, $128,7414$.

20 M.-N. Birkholz née Gensow, Z. Freixa and P. W. N. M. van Leeuwen, Chem. Soc. Rev., 2009, 38, 1099.

21 M.-Y. Jin and N. Yoshikai, J. Org. Chem., 2011, 76, 1972.

22 (a) K. Komeama, T. Kashihara and K. Takaki, Tetrahedron Lett., 2013, 54, 5659; (b) K. Komeyama, Y. Okamoto and K. Takaki, Angew. Chem., Int. Ed., 2014, 53, 11325; (c) R. Asakura, H. Fukuoka and K. Takaki, Tetrahedron Lett., 2015, 56, 1735.

23 F. Alois and N. Shi, J. Am. Chem. Soc., 1996, 118, 12349.

24 K. Namba and Y. Kishi, J. Am. Chem. Soc., 2005, 127, 15382.

25 (a) H. Fillon, C. Gosmini and J. Périchon, J. Am. Chem. Soc., 2003, 125, 3867; (b) M. Corpet and C. Gosmini, Chem. Commun., 2012, 48, 11561.

26 See ref. 13 and references therein.

27 See Table S1 in the ESI $\dagger$.

28 With Co catalyst: (a) K. Murakami, H. Yorimitsu and K. Oshima, Org. Lett., 2009, 11, 2373; (b) B.-H. Tan, J. Dong and N. Yoshikai, Angew. Chem., Int. Ed., 2012, 51, 9610. With Cr catalyst: (c) K.-I. Kanno, Y. Liu, A. Iesato, K. Nakajima and T. Takahashi, Org. Lett., 2005, 7, 5453.

29 A. B. Flynn and W. W. Ogilvie, Chem. Rev., 2007, 107, 4698.

30 With Pd catalyst: (a) M. Suginome, A. Yamamoto and M. Murakami, J. Am. Chem. Soc., 2003, 125, 6358; (b) M. Daini and M. Suginome, Chem. Commun., 2008, 5224; (c) M. Daini, A. Yamamoto and M. Suginome, J. Am. Chem. Soc., 2008, 130, 2918. With Ni catalyst: (d) A. Yamamoto and M. Suginome, J. Am. Chem. Soc., 2005, 127, 15706; (e) M. Suginome, M. Shirakura and A. Yamamoto, J. Am. Chem. Soc., 2006, 128, 14438. With Cu catalyst: $(f)$ R. Alfaro, A. Parra, J. Aleman, J. L. G. Ruano and M. Tortosa, J. Am. Chem. Soc., 2012, 134, 15165; $(g)$ L. Zhang, J. Cheng, B. Carry and Z. Hou, J. Am. Chem. Soc., 2012, 134, 14314; (h) H. Yoshida, I. Kageyuki and K. Takaki, Org. Lett., 2013, 15, 952; (i) K. Kubota, H. Iwamoto, E. Yamamoto and H. Ito, Org. Lett., 2015, 17, 620.

31 G.-H. Fang, Z.-J. Yan and M.-Z. Deng, Synthesis, 2006, 1148.

32 See Table $\mathrm{S} 2$ in the ESI $\dagger$.

33 J. J. Daly, R. P. A. Sneeden and H. H. Zeiss, J. Am. Chem. Soc., 1966, 88, 4287.

34 See Scheme S1 in the ESI†. 